\title{
Der gespiegelte Mensch
}

Erhard Taverna

Seit einigen Wochen werden im Swiss Medical Forum Artikel unter der Rubrik «Das MolekularMedizinische Teleskop» publiziert [1]. Einleitend wird moniert, dass die molekularbiologische Revolution unzählige Forschungsgruppen stillgelegt habe, die unvorbereitet für die neuen Gegebenheiten und deren Konsequenzen waren. So werde es auch jenen Ärztinnen und Ärzten gehen, die diese neuen Erkenntnisse nicht in die Praxis umsetzen könnten. Gesucht seien deshalb gute Lehrer/innen, die ihr Wissen grosszügig teilten. Gefragt seien einfühlsame Übersetzer mit didaktischem Geschick. Die Ausstellung «Der gespiegelte Mensch - In den Genen lesen» im Landesmuseum Zürich liefert einen guten Hintergrund zu der Forumfolge von PD Dr. med. Barbara Biedermann. Das Projekt von Life Science Zürich ist noch bis am 2. Januar 2005 $\mathrm{zu}$ besichtigen.

Das Herz der Ausstellung formt ein Fünfeck aus Stellwänden um ein Podest, von dem aus fünf Monitoren Doktoranden und Professoren über ihre Forschung sprechen. Die Innenseiten der hochformatigen Panels dienen als Projektionsflächen für Filmausschnitte, aussen herum tummeln sich in Vitrinen die lebenden Studienobjekte. An den Wänden des abgedunkelten Raumes leiten fünf Fragen zu den vertiefenden Informationen über. Dank der evolutionären Verwandtschaft erlauben die Modellorganismen Aussagen über biologische Vorgänge, die uns selber betreffen. Warum werde ich nicht grösser? Weshalb werden wir nicht alle gleich alt? Wozu braucht es Mann und Frau? Wie ist mein Körper gewachsen? Wie kann ich sehen? Antworten dazu liefern die identifizierten Wachstumsgene der Fruchtfliege, von denen 14 die Zellreaktionen auf Insulin steuern, was nebenbei neue Möglichkeiten für eine Krebstherapie eröffnet. Hinweise kommen vom Fadenwurm, dessen mutiertes Einzelgen eine verdoppelte Lebenszeit bewirkt. Vom Zebrafisch stammen Erkenntnisse über menschliche Augenerkrankungen, von der Hefezelle Auskünfte über Mutationen und Mitosen im Zellzyklus und vom Kreuzblütler Ackerschmalwand ein Modellsystem für Fragen nach der genetischen Prägung identisch gebauter weiblicher und männlicher Gene mit verschiedenen Auswirkungen. Das menschliche Genom spiegelt sich in den Genen der tierischen und

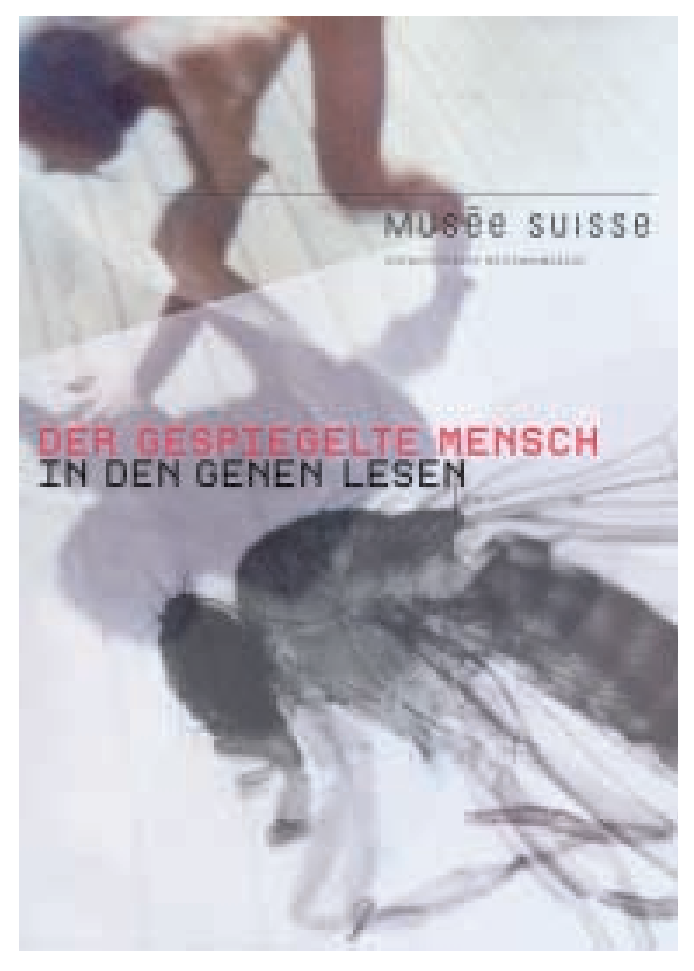

pflanzlichen Vertreter, die als Modellsysteme grundlegende Experimente zu biologisch-medizinischen Fragen zulassen. Es sind labortechnische Voraussetzungen, wie kurze Entwicklungszeiten, relativ wenige Körperzellen oder gute Haltbarkeit, die Hefe, Fadenwurm, Fruchtfliege, Zebrafisch und eine Wildpflanze zu Favoriten der Hochschulen machten. Im Raum nebenan stehen Mikroskopierplätze zur Verfügung, die mit vorbereiteten Experimenten Einblicke in die praktische Forschung an unseren Stellvertretern erlauben. Die Besucher können Fliegenmutanten, Würmer oder Lichtversuche an Fischen beobachten.

Die tägliche Forschungsarbeit ist das eigentliche Schwerpunktthema der Ausstellung. Die zahlreichen Bilder, Objekte, Kommentare und Projektionen kommen diesem Ziel didaktisch hervorragend nach. Landesmuseum, Life Science Zürich und die Pädagogische Hochschule Zürich haben gemeinsam ein Programm für alle Schulstufen erarbeitet, das auch ein Laborpraktikum beinhaltet. Führungen und ein Begleitprogramm erleichtern den Zugang zum anspruchsvollen Thema.
Das Molekular-Medizinische Teleskop. Schweiz Med Forum 2004;4(24):631. 
Im Leitfaden für eine wissenschaftliche Arbeit «Schweizer Jugend forscht» wird «wissenschaftlich» definiert als «systematische und nachvollziehbare Suche nach Wahrheit». Diesem Anspruch sind die Aussteller nachgekommen. Rund um das beschriebene Zentrum werden die existentiellen Lebensfragen veranschaulicht, die Grundbegriffe der Genetik erklärt und ihre Entdeckungsgeschichte zusammengefasst. Grossflächige Genomkarten von Mensch, Mücke und Fliege und ein Schema zu genetischen Krankheiten und Modellorganismen erklären fundiert, um was es hier geht. Ein abschliessender Raum der Reflexion lädt zum Sitzen und Verweilen ein. Bücher, Magazine und Internet gestatten vertiefende Analysen und Hinweise, ergänzt durch einen üppigen Büchertisch für gross und klein im Museumsshop.

Ideologische Spiegelfechtereien und utopische Spekulationen haben in dieser Arbeitswelt keinen Platz, doch jede Menge unvoreingenommene Neugierde und Staunen über das Wunder- bare. Der Grundton ist klar und nüchtern im Sinne von Karl Popper: «Wissenschaft wird immer eine Suche sein, niemals wirklich eine Entdeckung. Es ist eine Reise, niemals wirklich eine Ankunft.»

\section{Informationen zur Sonderausstellung:}

Schweizerisches Landesmuseum, Museumstrasse 2, 8001 Zürich, Tel. 0121865 11, www.dergespiegeltemensch.ch. Öffentliche Führungen jeden Dienstag um 18 Uhr.

\section{Weitere Informationen}

Bestellungen der Dokumentation und Anmeldung für Gruppen:

Tel. 0121865 04,

E-Mail: myriam.kunz@slm.admin.ch. 